\title{
ANALYSIS OF THE QUALITY OF THE WHOLE JOURNEY (DOOR-TO-DOOR) PASSENGER EXPERIENCE
}

\author{
María Dolores Herrero Tomás \\ Instituto Tecnológico del Embalaje, Transporte y Logística (ITENE), Spain \\ Emilio González Viosca \\ Instituto Tecnológico del Embalaje, Transporte y Logística (ITENE), Spain
}

\section{SUMMARY}

European cities increasingly face problems caused by transport and traffic. A key factor for all transport operators is the quality of the passenger experience as this particularly, affects the uptake of the service.

A comprehensive study (METPEX FP7 EU project - www.metpex.eu) developed by a consortium of 16 European partners has analysed the quality of the whole journey (door-todoor) passenger experience, including private or individual forms transport and attending to specific need of users' groups. For this purpose, a tool with a technological basis was used to collect data from 8 trial cities: Bucharest (Romania), Coventry (United Kingdom), Dublin (Ireland), Grevena (Greece), Rome (Italy), Stockholm (Sweden), Valencia (Spain) and Vilnius (Lithuania); and five FIA motorist networks countries.

For a correct evaluation of quality experience, it was deployed a subset of key variables derived from the comprehensive set of potential satisfaction factors that were studied for each pilot city.

In this paper, results of the travel experience are showed, including analysis of variables affecting behavior and feelings of passengers.

\section{METHODOLOGY USED TO ANALYSE THE QUALITY OF THE JOURNEY}

The aim of the study developed in METPEX lies in systemising and standardising the passenger satisfaction survey procedure by developing adaptable and adjustable measurement tools to be used by operators and any other interested partners. Since, the project aims to provide a general framework to facilitate the whole tools' design procedure for any interested party (such as public transport authorities, transport operators, survey designers, consultants), suggestions and recommendations should be provided on the selection of questions (variables) in specific circumstances and conditions. The central idea is to "filter/ sieve" the questions (variables) by prioritizing them according to agreed criteria. This allows the ranking of the variables and the usage/ selection of the most highly ranked ones when certain conditions are fulfilled. 
Based on the analysis, the syntheses and consolidation of the results of some research activities the diversity of variables to be included were defined. A lot of aspects that characterise the journey from different points of view are presented:

- Concepts related to journey

- Variables in relation to passenger experiences

- Variables related to the political aspects

- Variables related to the organisational aspects

- Variables related to the functional aspects

- Variables related to the environmental aspects

- Variables related to the technological aspects

- Variables related to the social aspects

In order to collect data about all this aspects, 5 different tools were developed and used:

- SBOING Navigator Survey Application

- METPEX Music App

- Web based survey form

- Paper based survey form

- Focus groups structured questionnaire

\section{VALIDATION OF THE SYSTEM (TRIALS)}

The objective of the testing activities is to develop technical and human interactions with the tools to guarantee operability, performance and usability of the system per customer specifications. There are many approaches to conduct validation and testing activities, depending on the existing constraints. These different approaches can be combined in different ways to answer to the requirements for different types of services, models, test objectives and levels of testing.

The testing activities are performed to ensure that the product is delivered correctly and satisfies the stakeholders' and users' needs. Testing activities were organized on several levels, namely:

- System testing: The objective of system testing is to verify that the integrated information system as a whole meets its specified requirements and satisfies both functional and nonfunctional design requirements (functional testing is concerned with what the system does whereas non-functional testing is concerned with how the system does what it does).

- System integration testing: The testing of the systems integration means the testing of packages and interfaces with external environment (e.g. Internet).

- User acceptance testing: In user acceptance testing, the user requirements are used to 
derive the functional hierarchy. The purpose of these activities is to test the functionality of the system as a whole in order to simulate the business processes including potentially non system procedures.

\section{SURVEY IMPLEMENTATION}

\subsection{Sample definition}

Since transport in cities deals with a multitude of different user types, of different transport modes, and within various sites, making sure that the sample size statistically reflects the structure of the population is of paramount importance. Adding to the complexity of the endeavour is the fact that we deal with relatively large populations.

Sometimes a population exhibits various properties which can only be identified in some population members. If these characteristics are relevant for the survey purpose, it is usually advisable to divide the population on a percentage basis accordingly.

In this case the stratification of travellers decided based on two different characteristics: the travel mode that respondents use on their main trip leg; and the user group in which they fall. With this approach, the travellers with different needs and vulnerable travellers (elderly, people with mobility impairment, etc.) will be included in the sampling.

The sampling process is based on the determination of several parameters that lead to the computing of a statistically representative sample size. The parameters that are set consider:

- Confidence level: it represents a measure on how often the true percentage of the population would pick an answer that lies within the confidence interval;

- Confidence interval (c): it represents a predetermined measure of the certainty that the structure of the provided answers is correct;

- Percentage picking a choice (p): represents a predetermined percentage that indicates what percentage of interviewed persons would pick a particular answer. This is an estimation of the truthfulness of the survey outcome. In this regard, setting the " $p$ " value to $50 \%$ is the most pessimistic scenario which leads to a highest sample size. As a way to achieve a higher quality assurance we used a $\mathrm{p}$ value of $50 \%$.

- Population size: the total number of our target population.

In order to determine the Z-score we must understand that it essentially represents whether a score is typical or atypical for a particular data set. Since we picked a standard confidence level of $95 \%$ we obtained the standard Z-score of 1.96 . The basic process of Z-score determination requires envisioning a bell curve distribution with the probability in each tail corresponding to half of the difference between $100 \%$ and confidence level 


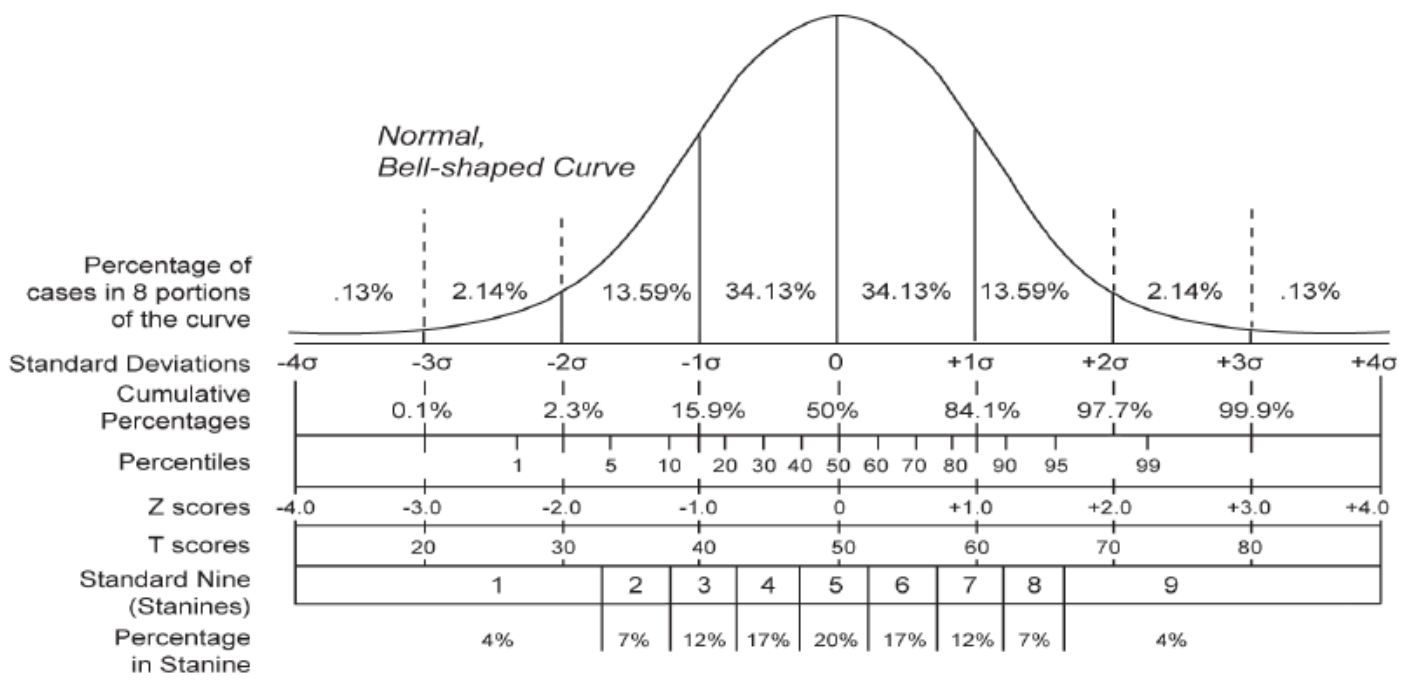

Fig. 1 - Normal Distribution and Z-score scales (Source: Wikipedia, 2014)

Using the computed Z-score and having set the parameters, we proceed by applying the following formula to determine the sample size for our survey:

$$
\begin{aligned}
\text { Sample size } & =\frac{Z^{2} p(1-p)}{c^{2}} \\
\text { Sample size final } & =\frac{\text { Sample size }}{1+\frac{\text { Sample size-1 }}{\text { Population }}}
\end{aligned}
$$

\subsection{Survey deployment}

The survey period lasted for a total of 45 days. Each city organized the data collection based on their targeted sample size, and goals by method/tool, by user group and by travel mode.

The recruitment method varied depending on the trial site and the collection method. The recruitment location also varied depending on the targeted user profile and travel mode. However, in most of cases, interviewers targeted their respondents at random specified locations where it was easier to engage a larger number of respondents.

In order to manage the quotas and reach the targets per user group and transport mode, the partners periodically checked their response statistics in the back-end system by user group, gender, age, etc. or by exporting their results (information on travel mode). Therefore, they were able to check if their data collection process was heading into the right direction, meaning that they were collecting the right amount of samples per each targeted group.

The Focus Groups were designed to collect data from the hard to reach user groups. The most commonly targeted groups were travellers with mobility impairments, with a wide range of communication and learning impairments or over 64s. The general working procedure of the Focus Groups involved gathering travellers from the same user group in a room, letting them fill in the common questionnaire, and with the help of a moderator, 
answer a preordained set of questions specifically for their transport group.

\section{SUMMARY OF DATA COLLECTED}

The trial period was developed in eight cities and five FIA motorist networks countries. These cities were Bucharest, Coventry, Dublin, Grevena, Rome, Stockholm, Valencia and Vilnius. FIA distributed the questionnaire among their motorist network in Germany, Poland, UK, France and Spain.

In the next table are showed he number of responses obtained in each city:

\begin{tabular}{|l|c|c|c|c|c|c|c|}
\hline \multicolumn{1}{|c|}{ City } & $\begin{array}{c}\text { Number } \\
\text { responses }\end{array}$ & $\begin{array}{c}\text { Paper/ } \\
\text { pencil }\end{array}$ & $\begin{array}{c}\text { Online } \\
\text { survey }\end{array}$ & $\begin{array}{c}\text { SbNavi } \\
\text { (iOS) }\end{array}$ & $\begin{array}{c}\text { SbNavi } \\
\text { (Android) }\end{array}$ & $\begin{array}{c}\text { Game } \\
\text { app }\end{array}$ & $\begin{array}{c}\text { Focus } \\
\text { group }\end{array}$ \\
\hline Bucharest & 457 & 59 & 316 & 9 & 4 & 46 & 23 \\
\hline Coventry & 479 & 321 & 104 & 9 & 0 & 33 & 12 \\
\hline Dublin & 573 & 231 & 297 & 11 & 0 & 29 & 5 \\
\hline Grevena & 320 & 150 & 65 & 7 & 1 & 2 & 95 \\
\hline Rome & 832 & 201 & 532 & 1 & 0 & 22 & 76 \\
\hline Stockholm & 996 & 305 & 252 & 206 & 5 & 228 & 81 \\
\hline Valencia & 680 & 22 & 600 & 13 & 4 & 41 & 0 \\
\hline Vilnius & 395 & 291 & 58 & 0 & 22 & 24 & 0 \\
\hline FIA network & 1611 & 0 & 1611 & 0 & 0 & 0 & 0 \\
\hline Total & 6343 & 1791 & 3835 & 256 & 36 & 425 & 292 \\
\hline
\end{tabular}

Tabla 1 - Summary of collected data and used survey methods

\begin{tabular}{|l|c|c|c|c|c|}
\hline \multicolumn{1}{|c|}{ City } & $\begin{array}{c}\text { Communication } \\
\text { impaired }\end{array}$ & Commuters & $\begin{array}{c}\text { Low } \\
\text { income }\end{array}$ & $\begin{array}{c}\text { Mobility } \\
\text { restricted }\end{array}$ & Elderly \\
\hline Bucharest & 10 & 75 & 57 & 20 & 21 \\
\hline Coventry & 10 & 88 & 14 & 6 & 18 \\
\hline Dublin & 9 & 292 & 42 & 11 & 12 \\
\hline Grevena & 2 & 9 & 48 & 26 & 40 \\
\hline Rome & 8 & 166 & 145 & 23 & 44 \\
\hline Stockholm & 7 & 99 & 56 & 68 & 45 \\
\hline Valencia & 9 & 76 & 191 & 22 & 67 \\
\hline Vilnius & 18 & 57 & 46 & 16 & 36 \\
\hline FIA & 160 & 234 & 235 & 59 & 51 \\
\hline Total* & 233 & 1092 & 834 & 251 & 334 \\
\hline
\end{tabular}

* Not all responses could be classified by user group

Tabla 2 - Classification of travellers into different user's groups (part 1) 


\begin{tabular}{|l|c|c|c|c|c|}
\hline \multicolumn{1}{|c|}{ City } & $\begin{array}{c}\text { Rural } \\
\text { dwellers }\end{array}$ & $\begin{array}{c}\text { With small } \\
\text { children }\end{array}$ & $\begin{array}{c}\text { With } \\
\text { dependents }\end{array}$ & $\begin{array}{c}\text { Young } \\
\text { travellers }\end{array}$ & Tourist \\
\hline Bucharest & 21 & 21 & 2 & 34 & 35 \\
\hline Coventry & 18 & 8 & 1 & 79 & 69 \\
\hline Dublin & 22 & 5 & 3 & 43 & 8 \\
\hline Grevena & 27 & 32 & 0 & 55 & 24 \\
\hline Rome & 47 & 5 & 5 & 185 & 44 \\
\hline Stockholm & 13 & 59 & 0 & 84 & 18 \\
\hline Valencia & 7 & 19 & 4 & 34 & 34 \\
\hline Vilnius & 3 & 35 & 1 & 36 & 4 \\
\hline FIA & 144 & 31 & 27 & 110 & 170 \\
\hline Total & 302 & 214 & 43 & 660 & 406 \\
\hline
\end{tabular}

Tabla 3 - Classification of travellers into different user's groups (part 2)

\begin{tabular}{|l|c|c|c|c|c|c|c|}
\hline \multicolumn{1}{|c|}{ City } & $\begin{array}{c}\text { Private } \\
\text { vehicle }\end{array}$ & $\begin{array}{c}\text { PT } \\
\text { Road }\end{array}$ & $\begin{array}{c}\text { PT } \\
\text { Rail }\end{array}$ & $\begin{array}{c}\text { Pedestrian } \\
\text { /Bike }\end{array}$ & $\begin{array}{c}\text { PT } \\
\text { Waterborne }\end{array}$ & DRT* & $\begin{array}{c}\text { Mobility } \\
\text { vehicles }\end{array}$ \\
\hline Bucharest & 75 & 108 & 154 & 46 & 0 & 20 & 3 \\
\hline Coventry & 129 & 91 & 98 & 66 & 0 & 15 & 2 \\
\hline Dublin & 31 & 389 & 104 & 19 & 1 & 1 & 0 \\
\hline Grevena & 98 & 154 & 8 & 62 & 6 & 1 & 0 \\
\hline Rome & 232 & 184 & 362 & 26 & 1 & 0 & 5 \\
\hline Stockholm & 168 & 160 & 367 & 109 & 3 & 20 & 0 \\
\hline Valencia & 178 & 110 & 61 & 291 & 0 & 0 & 0 \\
\hline Vilnius & 121 & 146 & 5 & 92 & 0 & 6 & 4 \\
\hline FIA & 639 & 297 & 427 & 151 & 21 & 19 & 57 \\
\hline Total** & 1693 & 1652 & 1616 & 874 & 32 & 82 & 71 \\
\hline
\end{tabular}

* Demand Responsive Transit

** Not all responses could be classified by travel mode

Tabla 4 - Distribution of valid respondents by travel mode

\section{DESCRIPTIVE ANALYSIS FROM THE SURVEY RESULTS}

The descriptive analyses towards travellers' socio-demographic characteristics showed that data collected had a relatively gender balanced sample. However, at the same time, the sample was overrepresented in terms of younger, lower income, and lower educated travellers, and underrepresented for older travellers. On the other hand, the proportion of travellers that reported any kind of disability was similar to the estimated population within European regions.

The descriptive analyses towards travellers' reported journey characteristics showed that 
commuting to/from work and education related trip purposes represented the largest portion of the trips (44\%), followed by leisure journeys (20\%) and shopping and work related trips (10\%). The exceptions were Valencia, Grevena and FIA where leisure and shopping trips made up $40 \%$. Most of those trips (58\%) were executed more often than twice a week, with a range of between 11 to 60 minutes of travel time. The average number of trip stages was 1.92 , with public transport modes the most common mode in trip legs, followed by soft modes (walking and cycling) and private motorised travel modes.

The descriptive analyses towards travellers' reported travel satisfactions show that travellers with small children, visitors/tourists, and the elderly reported the highest travel satisfaction, whilst commuters, young travellers, rural dwellers, and the mobility restricted travellers reported otherwise. The travellers who used demand responsive travel modes, travelled onfoot, and used private motorised vehicles reported the highest satisfaction scores, whilst those who used public transport modes reported the lowest travel satisfaction. The overall travel satisfaction was highest among travel which was less than 20 minutes, and lowest among journeys which took between 61 and 90 minutes. Escorting children, escorting dependents, visiting the city and leisure trips reported the highest travel satisfaction, whilst commuting to work, commuting back home, work related and education received the lowest travel satisfaction. Safety and reliability were generally the attributes with the highest positive perception among participants while value for money and ticketing options were the worst perceived.

Further multivariate analyses towards travellers' overall travel satisfaction found that except among FIA respondents - there was no significant difference between different gender groups in terms of reported overall travel satisfaction. Those between 65-74 years old in Stockholm reported the lowest travel satisfactions compared to other age groups, whilst the same age group in Vilnius was the most satisfied with their travel experience. Age groups were not found significant in influencing travellers' travel satisfaction at Bucharest, Coventry, Dublin, Grevena, and Rome. Travellers' income, occupation, residential areas and education levels were also found to not have any significant impact on travellers' overall travel satisfaction. Travellers who have had a previously bad experience reported a significantly lower travel satisfaction than other travellers. Furthermore, the more frequent the trip, the least satisfied the travellers from Rome and FIA network were. However, the impacts of the frequency are less clear for travellers from other test sites.

In line with previous studies, the travellers who were in sad/lower mood conditions reported significantly lower travel satisfaction than their counterparts. Tourist/visitors reported higher travel satisfaction in Bucharest and Grevena, whilst commuters and younger travellers were the least satisfied with their travel in Stockholm. Low income travellers and individuals who travel with children reported highest travel satisfaction among Valencian respondents, whilst rural dwellers and mobility restricted travellers reported significantly lower travel satisfactions among Vilnius travellers. There were not any significant differences on 
reported travel satisfaction among different traveller groups in Coventry, Dublin, FIA motorist network and Rome. After all other variables being controlled, different survey method performed better in different sites. This may be related to the survey methods that were familiar in different test sites.

\section{CONCLUSION}

Whilst different group of travellers may value and expect different type of services, the repetitively mentioned issue which seems apply to many, if not most, of travellers groups is improving first and last mile facilities. This may include from improving the directness of the pedestrian routes to increase the accessibility of station facilities and platforms. In accommodating special needs for different user groups, the required measures to increase first and last mile experience are also varied. These could go from increasing the clarity of signage to other forms of transport (visitors) to implement a ticket integrated policy (commuters). In single stage trips, overall, stakeholders should focus on improving the onboard conditions in terms of comfort and level of crowding, on increasing the parking availability and the reliability of the service. Given that different users have different needs, if aiming to increase specific user groups ${ }^{\prime}$ travel satisfaction tailor made policies directed to each of these groups is suggested.

\section{ACKNOLEDGEMENTS}

This study is part of the METPEX (MEasurement Tool to determine the quality of the Passenger EXperience) project (www.metpex.eu), which has received funding from the European Union's Seventh Framework Programme for research, technological development and demonstration under grant agreement no 314354.

In this data collection and the correspondent associated analysis have participated partners from different companies in Europe, being all of them part of METPEX Project consortium: KTH in Stockholm (Yusak O. Susilo and Roberto Fernández), University of Coventry in United Kingdom (Andree Woodcock and Jane Osmond), SBOING in Greece (Fotis Liotopoulos), VTM in Portugal (Andre Duarte and Tiago Pimentel), INTECO in Bucharest (Lucian Emanuel Anghel and Rodica Hrin), Eurokleis in Rome (Federico Fornari), FIA in Brusssels (Virginie Tolio and Victor Brangeon), Interactions in Dublin (Eileen O'Connell and John Porter), Smart Continent in Vilnius (Ieva Markucevičiūtè and Andrius Jarzemskis), ANGRE in Grevena (Chrysoula Krithariotik) and Politecnico di Torino in Italy (Marco Diana and Miriam Pirra).

\section{REFERENCES}


METPEX (2013). Development of standard format for the measurement instruments. Deliverable 3.1.

METPEX (2014). Report on survey and data collection processes at each location. Deliverable 4.1.

METPEX (2015). Report on survey results and behavioural analyses from each location. Deliverable 4.2. 